\title{
Políticas públicas de esporte e lazer nas cidades: aspectos socioeconômicos e geográficos do Programa de Esporte e Lazer nas Cidades - PELC, do Ministério do Esporte
}

\author{
Júlio Ferreira da Costa Neto ${ }^{1}$ \\ Renata Aparecida Elias Dantas ${ }^{2}$
}

\section{Resumo}

Este estudo analisa o Programa Esporte e Lazer das Cidades - PELC, do Ministério do Esporte. Inicialmente, foram levantados os dados sobre o PELC e os núcleos de responsabilidade de avaliação pelo Centro de Desenvolvimento do Esporte Recreativo e do Lazer, da Faculdade de Educação Física da UnB. De modo geral, os núcleos se localizam em áreas do Distrito Federal e do município de Valparaiso - GO, caracteristicamente de baixa renda, onde as famílias sobrevivem com até dois salários mínimos e possuem até cinco pessoas em média. O objetivo principal do trabalho foi a realização de uma avaliação inicial dos aspectos socioeconômicos e geográficos do PELC, em relação à aplicação de políticas públicas voltadas para as populações de baixa renda, especificamente nos núcleos do Programa no Distrito Federal em um município do Entorno. Foram aplicados questionários aos participantes do programa com o intuito de avaliar o nível de renda dos familiares e obter o perfil social das comunidades atendidas. Todos os núcleos foram localizados geograficamente com a utilização de ferramentas de geoprocessamento. Ao atender comunidades carentes, o Programa complementa alguns aspectos dos programas sociais desenvolvidos pelo governo federal e pelo Distrito Federal. As políticas públicas elaboradas com o objetivo de equalizar os problemas urbanos e também do esporte e do lazer poderiam trabalhar as questões comuns desses dois temas, de modo a aproveitar melhor os espaços públicos e promover atividades que envolvessem as comunidades que habitam essas áreas urbanas modernas.

1 Professor do curso de Geografia - UniCEUB; Analista Ambiental do CECAV/ICMBIO; Mestre em Geografia pela Universidade de Brasília - UnB; Bacharel em Educação Física - UniCEUB. juliofcneto@uol.com.br.

2 Professora do curso de Educação Física do UniCEUB, Mestre e doutoranda em Ciências da Saúde pela Universidade de Brasília - UnB. profrenataelias@yahoo.com.br. 
Verificou-se que, no caso do PELC, a maior parte dos responsáveis pelos núcleos - os coordenadores ou os agentes sociais de esporte e lazer - não tinha a formação necessária à execução dos objetivos do programa.

Palavras-chave: Esporte. Lazer. Cidades. Políticas públicas.

\section{Introdução}

De acordo com Castellani Filho (2007), o PELC teve início em 2003 e atualmente tem atuação e ações em todos os estados brasileiros. Desde 2008, todo o Programa vem passando por uma série de avaliações em vários aspectos da sua institucionalização.

O PELC é um programa social do Ministério do Esporte e faz parte do quadro das políticas sociais do atual governo brasileiro. Tem como meta a democratização do acesso às manifestações culturais, no campo do esporte e lazer, e atende a crianças, jovens, adultos, idosos e pessoas com deficiência, preferencialmente no meio urbano. Esse Programa possui uma política de formação para os trabalhadores que atuam em seus quadros, os denominados agentes sociais de esporte e lazer, responsáveis pela mediação dos conteúdos culturais do lazer nas comunidades participantes do programa (BRASIL, 2010a).

A sistemática de seleção dos núcleos participantes do PELC em todo Brasil envolve a elaboração pelos interessados de um projeto que atenda todos os itens constantes em um edital publicado pelo Ministério do Esporte em seu site na Internet (BRASIL, 2010a).

Segundo o Instituto Brasileiro de Geografia e Estatística (IBGE) a maior parte da população brasileira hoje já vive nas cidades. Estas, pela complexidade que possuem, exigem cada vez mais políticas de gestão dos espaços e territórios onde se inserem que sejam condizentes com a realidade atual da sociedade brasileira (IBGE, 2007). 
As políticas públicas, segundo Vieira e Bredariol (1998, p. 77), de uma maneira bastante simples, podem ser definidas como “[...] um conjunto de ações de organismos estatais com o objetivo de equacionar ou resolver problemas da coletividade".

Existe uma distinção entre as políticas públicas de Estado e as políticas de governo. A primeira diz respeito à definição citada anteriormente e tem um caráter permanente; são as tarefas que o Estado tem que cumprir. O exemplo que demonstra bem essa distinção é o caso de duas políticas públicas que tratam da área ambiental, a Política Nacional de Meio Ambiente e a Política Nacional de Recursos Hídricos (VIEIRA; BREDARIOL, 1998).

O segundo diz respeito a um programa de governo ligado a um mandato eletivo com duração de quatro anos (VIEIRA; BREDARIOL, 1998). O exemplo que pode ser dado nesse caso é o Programa de Esporte e Lazer nas Cidades - PELC, do atual governo brasileiro.

Dessa forma, cada vez mais se mostra importante o estabelecimento de políticas públicas ${ }^{3}$ com o objetivo de equacionar problemas que atingem a sociedade nas áreas urbanas, ou melhor, nas cidades. Dentre essas, a que nos interessa nesta pesquisa é a de esporte e lazer, objeto do PELC, do Ministério do Esporte.

Em função do exposto e da necessidade do profissional de Educação Física em participar cada vez mais da proposição, planejamento, organização e execução desse tipo de política, estabeleceu-se como objetivo principal desta pesquisa a realização de uma breve avaliação do Programa de Esporte e Lazer nas Cidades - PELC , do Ministério do Esporte, em relação aos aspectos da aplicação das

3 Políticas públicas “[...] representam a materialidade da intervenção do Estado, ou do Estado em Ação; entende ainda que, em um plano mais concreto, 'o conceito de políticas públicas implica considerar os recursos de poder que operam na sua definição e que têm nas instituições do Estado, sobretudo na máquina governamental, o seu principal referente" (AZEVEDO, 1997, p. 5).

4 Pesquisa financiada pela FINEP, por meio do Edital 2006-1 C\&T para o Esporte, 2006-2008. 
políticas públicas voltadas para as populações de baixa renda, especificamente nos núcleos do Programa no Distrito Federal em um município do Entorno.

\section{As cidades e a urbanização}

Segundo Santos (1992), a cidade poderia ser compreendida como o local onde tudo se processa e interage, onde ocorrem as relações sociais e humanas e também onde estão localizadas as classes sociais, a produção industrial e a divisão do trabalho. Segundo Geiger (1995), as cidades possuem uma complexidade ímpar e é exatamente nelas que ocorrem as relações sociais e os maiores embates.

Como falar da urbanização e das cidades sem tratar também do planejamento necessário à melhor disposição dos equipamentos mínimos para o seu funcionamento? Dessa forma, Hattner (1978) afirma que o planejamento urbano das cidades envolve a tentativa de manutenção de certo controle dos movimentos naturais das migrações populacionais e, consequentemente, envolve também as relações sociais entre os homens e o meio em que vivem.

Reforçando essa ideia, Hattner (1978) afirma que, melhorando ou organizando melhor a ocupação dos espaços das áreas urbanas, ocorrerá consequentemente uma melhoria nas relações sociais e no estilo de vida das populações residentes nas regiões com essas características. Essa afirmação como postulado vem sendo muito utilizada como modelo para os planejadores modernos.

Dentro da mesma ótica do planejamento urbano, Oligari (2002) defende que somente com o planejamento é que o poder público pode minimizar os mais variados problemas das grandes cidades ou das áreas urbanas. A busca seria sempre pela governabilidade. 


\section{Políticas públicas de esporte e lazer}

Os Art $6^{\circ}$ e $217^{\circ}$ da Constituição Federal Brasileira de 1988 tratam exatamente da questão da participação do Estado nos processos ligados à Educação Física, ao esporte e ao lazer. Estabelecem claramente que é dever do Estado fomentar práticas esportivas como direito de cada um, observando algumas ressalvas. Essa nova ordem jurídica determina a descentralização no que se refere ao desenvolvimento de ações, programas e projetos em todos os setores de atuação, consequentemente, o sistema de educação física e desporto segue essa orientação (BRASIL, 1988; BRUST; BAGGIO; SALDANHA FILHO, 2006).

Adams (2009) evidencia que o esporte pode ocorrer com fins de lazer ou de competição profissional. Os praticantes das modalidades esportivas é que vão dar o sentido de competição ou diversão, dependendo do contexto social em que estão inseridos. No caso do PELC, o esporte é tratado como uma atividade recreativa, lúdica e com objetivo de promover a satisfação e a diversão.

Em relação ao lazer, pode-se dizer que está ligado essencialmente ao tempo livre e aos momentos de repouso e de diversão, sem nenhuma preocupação com as obrigações profissionais, familiares ou sociais (DUMAZEDIER, 2001).

\section{Tecnologias de auxílio na localização espacial das políticas públicas}

Para a avaliação da efetividade de qualquer tipo de política pública é necessário a utilização de tecnologias que mostrem a localização exata onde elas são aplicadas. Dessa forma, utilizar mapas digitais e tecnologias apropriadas para localizar fenômenos é fundamental. É importante saber onde tais políticas públicas de cunho social estão acontecendo. 
Diante disso, atualmente tem-se como instrumento o Geoprocessamento, que envolve a utilização de um conjunto de tecnologias para coleta, processamento, análise e oferta de informações com referência geográfica (ROSA, 2005). Ele representa qualquer tipo de processamento de dados georreferenciados e, ainda segundo Rosa (2005), envolve pelo menos quatro categorias de técnicas que estão relacionadas ao tratamento da informação espacial:

- Técnicas para coleta de informação espacial;

- Técnicas de armazenamento de informação espacial;

- Técnicas para tratamento e análise de informação espacial; e

- Técnicas para uso integrado de informação espacial com os sistemas SIG (Sistemas de Informações Geográficas).

De modo geral, o Geoprocessamento envolve a utilização de várias ciências e técnicas indispensáveis ao seu desenvolvimento, como a Cartografia, a Geodésia, a Geografia, a Informática, a Ciência Espacial, o GPS, os bancos de dados e a Internet. Além desses, podemos citar como componentes importantes o uso dos Sistemas de Informações Geográficas - SIG, os programas de Processamento Digital de Imagens de satélite ou Sensoriamento Remoto - SR.

No tipo de trabalho de pesquisa que foi desenvolvido, o uso do Sistema de Informações Geográficas - SIG se mostra uma ferramenta importante e uma forma de realização das análises relativas à localização dos núcleos do PELC nas regiões administrativas do Distrito Federal participantes do Projeto.

\section{Aspectos do PELC}

O PELC é gerenciado pela Secretaria Nacional de Desenvolvimento do Esporte e do Lazer (SNDEL) e justifica sua existência às desigualdades ainda existentes de acesso ao esporte e lazer por uma parcela grande da população do Brasil. Tem como objetivos principais ampliar, democratizar e universalizar o acesso à prática e ao conhecimento do esporte recreativo e de lazer, integrando suas ações 
às demais políticas públicas, favorecendo o desenvolvimento humano e a inclusão social (BRASIL, 2010a).

Um dos itens mais importantes na implementação do PELC nos municípios brasileiros é o processo de treinamento e formação continuada dos chamados agentes sociais de esporte e lazer. Esse processo envolve cursos promovidos pelo próprio Ministério do Esporte no sentido de capacitar os responsáveis pela execução desse tipo de trabalho social. Não necessariamente esses agentes são formados em Educação Física, o que pode ser um ponto nevrálgico da implantação do programa (SUASSUNA, 2009).

Os eixos principais do PELC são: Funcionamento de Núcleos de Esporte Recreativo e de Lazer, Funcionamento da Rede CEDES (Centros de Desenvolvimento de Esporte Recreativo e de Lazer), Implantação e Modernização de Infraestrutura para Esporte Recreativo e Lazer (BRASIL, 2010a).

Segundo Mendes e Cunha Júnior (2009), em 2007, o PELC contava com 1.288 núcleos distribuídos em 405 municípios e 19 estados, mais o Distrito Federal. Isso demonstra a abrangência nacional do Programa em avaliação.

O último edital publicado pelo Ministério do Esporte (Edital Portaria 001 de 06/01/2010), chamando os interessados a participarem do Programa, resultou na seleção de 80 novas entidades públicas e privadas (BRASIL, 2010b). Essas entidades têm um prazo estipulado para cumprirem as exigências legais para serem efetivas no programa.

\subsection{Aspectos do PELC no Distrito Federal e no Entorno}

Os núcleos do PELC no Distrito Federal e no Entorno desenvolvem uma série de atividades voltadas para o esporte, o lazer a cultura. As principais atividades podem ser vistas no quadro abaixo: 
Quadro 1 - Principais atividades desenvolvidas nos núcleos do PELC no Distrito Federal e em Valparaíso de Goiás.

\begin{tabular}{|c|c|c|c|c|c|c|}
\hline $\begin{array}{c}\text { Atividades } \\
\text { Esportivas/ } \\
\text { Lazer/ } \\
\text { Culturais } \\
\end{array}$ & $\begin{array}{c}\text { Associação } \\
\text { de Capoeira } \\
\text { Ladainha }\end{array}$ & $\begin{array}{l}\text { Instituto } \\
\text { Arte Cia. e } \\
\text { Cidadania }\end{array}$ & ARUREMAS & ARUC & $\begin{array}{c}\text { Centro } \\
\text { Cultural } \\
\text { Vem } \\
\text { Viver } \\
\end{array}$ & JUDEC \\
\hline Artesanato & & & & & $x$ & $x$ \\
\hline Canto coral & & & & & $\mathrm{X}$ & $x$ \\
\hline Capoeira & $X$ & & & & $X$ & $\mathrm{X}$ \\
\hline Capoterapia & & $x$ & & & & \\
\hline Futebol & $x$ & $x$ & $x$ & $x$ & $x$ & $x$ \\
\hline Handebol & $\mathrm{X}$ & & & & & \\
\hline Ginastica & $x$ & & & & & \\
\hline Recreação & $x$ & & & & & \\
\hline Queimada & $x$ & & & & & \\
\hline Dança & & & & $\mathrm{X}$ & $\mathrm{X}$ & $\mathrm{X}$ \\
\hline Violão & & & & & $x$ & $x$ \\
\hline Teclado & & & & & $x$ & $x$ \\
\hline Muai Thay & & & & & $x$ & $x$ \\
\hline Teatro & & & & & $\mathrm{X}$ & \\
\hline Taekwondo & & $\mathrm{X}$ & & $\mathrm{X}$ & & \\
\hline Jiu Jitsu & & $\mathrm{X}$ & & $x$ & & \\
\hline Hip Нор & & & & & $x$ & $x$ \\
\hline Judô & & & & $\mathrm{X}$ & & \\
\hline Voleibol & $\mathrm{X}$ & & & $\mathrm{X}$ & & \\
\hline Xadrez & & & & & $x$ & $x$ \\
\hline Outros & & & & $x$ & & \\
\hline
\end{tabular}

Fonte: dos autores. 


\section{Aspectos socioeconômicos do Distrito Federal}

Ao longo dos anos, o Distrito Federal vem seguindo os mesmos padrões de crescimento e ocupação dos territórios das demais capitais do país. Segundo o último censo do IBGE (2007), a população residente no DF seria de 2.455.903 habitantes. Desse total, aproximadamente 95\% reside nas áreas urbanas (DISTRITO FEDERAL, 2008).

De uma maneira geral, a distribuição de renda no DF também tem se comportado como no país todo, de maneira bem desigual. Segundo o GDF (DISTRITO FEDERAL, 2008), as maiores rendas per capitas do DF se concentram no Plano Piloto, Lagos Sul e Norte, Sudoeste e Águas Claras (Gráfico 1). Da mesma forma, é possível identificar as menores rendas, notadamente nas regiões administrativas de Itapoã, Varjão, Recanto das Emas, Planaltina, Santa Maria e Estrutural.

Gráfico 1 - Distribuição da renda per capita da população do DF por Região Administrativa.

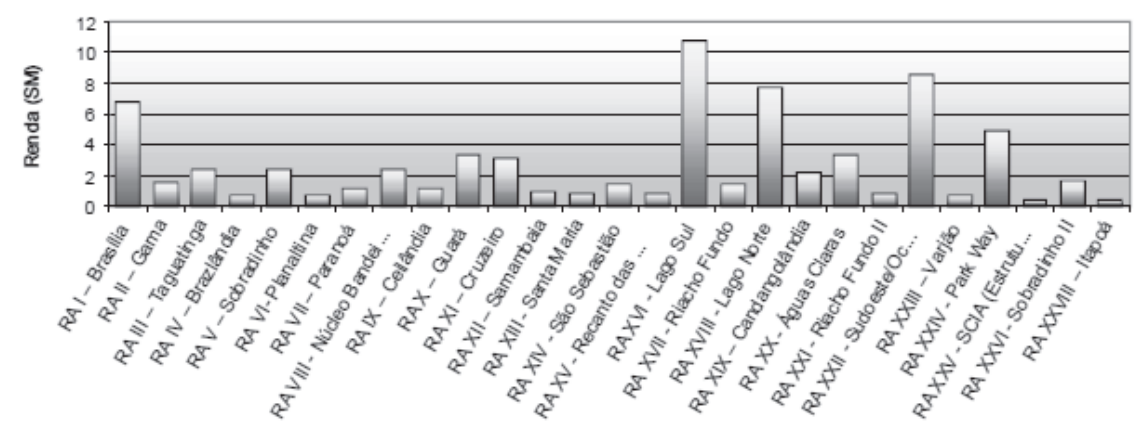

Regiōes Administrativas

Fonte: GDF (DISTRITO FEDERAL, 2008).

Essas desigualdades impõem a necessidade premente da atuação do poder público, no sentido de promover ações voltadas para a melhoria das condições sociais das populações menos privilegiadas que ocupam as áreas periféricas do DF (FIGUEIREDO, 2009). Dessa forma, surgiram ao longo dos últimos anos políticas de governos local e federal, que tentaram minimizar problemas sociais. Surgem as chamadas bolsas sociais que tentam reduzir as desigualdades de renda, intimamente ligados ao acesso à educação, ao lazer e à consequente diminuição da violência urbana. 


\section{Metodologia}

Esse estudo foi submetido ao Comitê de Ética em Pesquisa - CEP, do Centro Universitário de Brasília - UniCEUB, e foi aprovado com o parecer CAAE 4333/10 TCC 166/10.

$\mathrm{Na}$ execução da pesquisa, foram inicialmente levantados os dados sobre o Programa PELC - ME e os núcleos de responsabilidade de avaliação pelo Centro de Desenvolvimento do Esporte Recreativo e do Lazer - CEDES, da Faculdade de Educação Física da UnB. Os núcleos foram localizados e georreferenciados com a utilização de um sistema de posicionamento global, um GPS. Esse equipamento/ sistema nos deu a localização em coordenadas geográficas (Projeção Geográfica, Datum SAD69) a partir de uma visita a cada um dos núcleos avaliados. Os núcleos localizados foram: a Associação de Capoeira Ladainha, de Taguatinga, o Instituto Arte Cia e Cidadania, de Samambaia, a Associação Recreativa Desportiva e Cultural Unidos do Recanto das Emas - ARUREMAS, do Recanto das Emas, a Associação Recreativa Cultural Unidos do Cruzeiro - ARUC, do Cruzeiro, o Centro Cultural Vem Viver e o Grupo Jovens Unidos para o Desenvolvimento Cultural - JUDEC, em Valparaíso de Goiás (Figura 1).

Os pontos de localização foram transferidos para o sistema de informações geográficas - SIG, o ARCGIS 9.3, no laboratório de Geoprocessamento do UniCEUB, de modo a compor a base de dados geográficos digitais da pesquisa. A base de dados é formada pelas informações: hidrografia, estradas e rodovias, vias urbanas, limites das regiões administrativas (RAs) do Distrito Federal, limite do município de Valparaíso de Goiás, localização das escolas públicas e particulares das RAs, localização dos equipamentos de esporte e lazer, atualizados até 1998.

À localização dos núcleos foram associadas informações cadastrais sobre os responsáveis, o endereço, número aproximado de atendidos, endereço dos atendidos, se os atendidos recebem bolsas sociais dos governos locais e federal, além de outras. Essas informações serviram para avaliar o raio de atuação e abrangência dos núcleos em relação à população atendida. 
Os dados socioeconômicos relativos aos núcleos do Projeto e das RAs foram coletados por meio de levantamentos bibliográficos, e os questionários aplicados nos núcleos foram digitalizados e inseridos no programa estatístico SPSS 13, no qual foi possível realizar uma série de cruzamentos de tabelas e executar algumas análises na avaliação das questões ligadas à socioeconomia do Programa.

\section{Aspectos socioeconômicos presentes nos núcleos do projeto}

Em números gerais, todos os núcleos do PELC no Distrito Federal e mais o município de Valparaíso de Goiás atendem a aproximadamente 3.000 pessoas diariamente. Para avaliar alguns aspectos socioeconômicos relativos aos atendidos pelo Programa, foram aplicados questionários procurando identificar qual o nível de renda familiar, o número de pessoas na família, o endereço onde residem, quais as atividades que praticavam no núcleo, os motivos de escolha de determinado núcleo e os meios de transportes utilizados para deslocamento até os núcleos. Foram aplicados mais de 300 questionários, mas somente 292 foram totalmente preenchidos e devolvidos à coordenação de avaliação do Projeto, no NECON/CEDES/UnB.

O número de questionários respondidos não representa logicamente a totalidade dos atendidos e, em termos estatísticos, talvez também não fosse considerado significativo para alguns tipos de análises. Mesmo assim, foi possível extrair informações importantes para subsidiar tomadas de decisões futuras em termos de políticas públicas de esporte e lazer. Os questionários devolvidos representam aproximadamente $10 \%$ do total de atendidos pelo programa PELC.

A tabela 1 destaca o número de participantes dos projetos por cidade onde residem e também a quantidade de questionários respondidos para cada localidade. Em alguns casos, o atendido mora em um local e frequenta um núcleo em outra cidade; por exemplo, o caso do núcleo da ARUC, no Cruzeiro, onde 20,5\% dos atendidos residem próximo a ele e 11,3\% moram na Estrutural, de renda familiar muito baixa e infraestrutura de equipamentos de esporte e lazer bem precários, o que justifica o deslocamento para a cidade mais próxima. 
Figura 1 - Núcleos do Programa PELC do Ministério do Esporte no Distrito Federal.

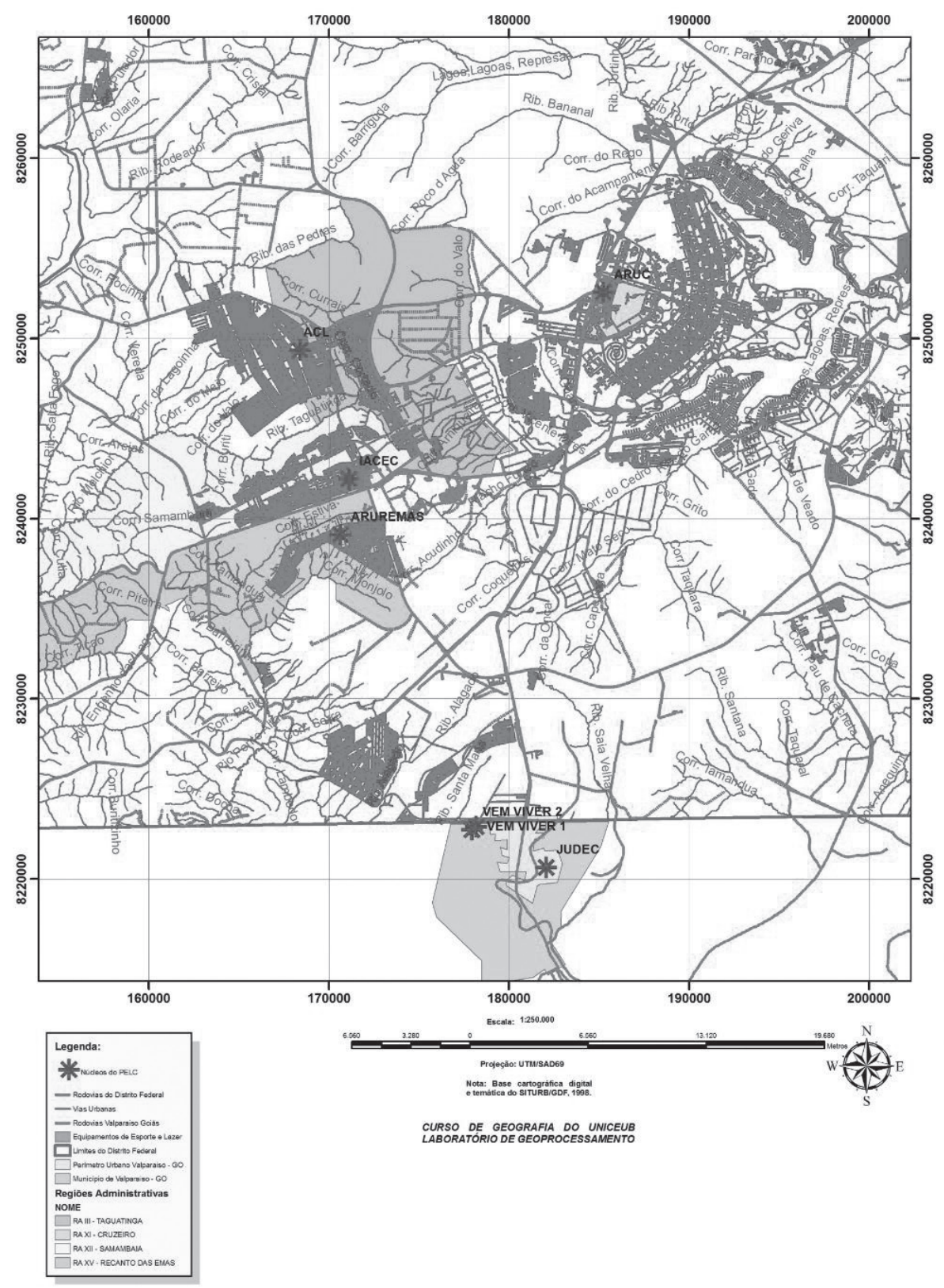

Fonte: dos autores. 
Tabela 1 - Cidade em que reside o atendido.

\begin{tabular}{|c|c|c|c|}
\hline Cidade & No & Percentual (\%) & Percentual Válido (\%) \\
\hline Valparaíso & 92 & 31,5 & 34,3 \\
\hline Cruzeiro & 60 & 20,5 & 22,4 \\
\hline Estrutural & 33 & 11,3 & 12,3 \\
\hline Samambaia & 24 & 8,2 & 9 \\
\hline Taguatinga & 17 & 5,8 & 6,3 \\
\hline Ceilândia & 13 & 4,5 & 4,9 \\
\hline Santa Maria & 7 & 2,4 & 2,6 \\
\hline Vicente Pires & 4 & 1,4 & 1,5 \\
\hline Sudoeste & 3 & 1 & 1,1 \\
\hline Asa Norte & 2 & 0,7 & 0,7 \\
\hline Cruzeiro do Sul & 2 & 0,7 & 0,7 \\
\hline Planaltina & 2 & 0,7 & 0,7 \\
\hline SAI & 2 & 0,7 & 0,7 \\
\hline Águas Claras & 1 & 0,3 & 0,4 \\
\hline Águas Lindas & 1 & 0,3 & 0,4 \\
\hline Guará & 1 & 0,3 & 0,4 \\
\hline Jardim Ingá & 1 & 0,3 & 0,4 \\
\hline Park Way & 1 & 0,3 & 0,4 \\
\hline Parque Mingone II GO & 1 & 0,3 & 0,4 \\
\hline Sobradinho & 1 & 0,3 & 0,4 \\
\hline Total & 268 & 91,8 & 100 \\
\hline Não responderam & 24 & 8,2 & \\
\hline Total Geral & 292 & 100 & \\
\hline
\end{tabular}

Fonte: dos autores.

Outro aspecto importante, em se tratando de analisar que tipo de população os programas governamentais atingem, é a renda familiar. No caso dos núcleos do PELC avaliados, foi possível identificar que 14,08\% vivem com menos de um salário mínimo, que $50 \%$ com um ou dois salários e com três ou mais salários, 35,92\% (Tabela 2 e Gráfico 2). Esses percentuais demonstram que, de certa forma, o Programa atinge uma população realmente carente e necessitada. 
Tabela 2 - Renda familiar dos atendidos pelo PELC

\begin{tabular}{|l|c|c|c|}
\hline $\begin{array}{c}\text { Renda familiar dos } \\
\text { Atendidos pelo PELC }\end{array}$ & Frequência & Percentual (\%) & $\begin{array}{c}\text { Percentual } \\
\text { Válido (\%) }\end{array}$ \\
\hline $\begin{array}{l}\text { Menos de um salário mínimo } \\
(\mathrm{R} \$ 415,00)\end{array}$ & 40 & 13,70 & 14,08 \\
\hline Um salário mínimo (R\$ 415,00) & 69 & 23,63 & 24,30 \\
\hline Dois salários mínimos (R\$ 830,00) & 73 & 25,00 & 25,70 \\
\hline Três salários mínimos (R\$ 1.245,00) & 47 & 16,10 & 16,55 \\
\hline Mais de três salários mínimos & 55 & 18,84 & 19,37 \\
\hline Total & $\mathbf{2 8 4}$ & 97,26 & 100 \\
\hline Não responderam & 8 & 2,74 & \\
\hline Total & $\mathbf{2 9 2}$ & $\mathbf{1 0 0}$ & \\
\hline
\end{tabular}

Fonte: dos autores.

Gráfico 2 - Renda familiar dos atendidos pelo PELC

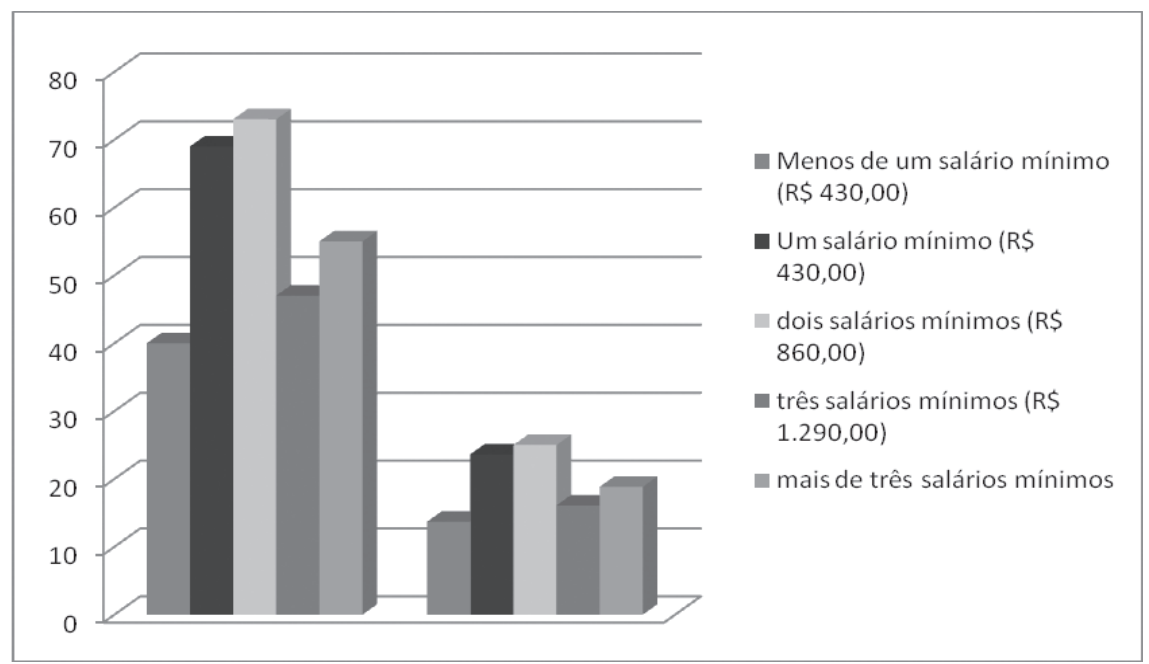

Fonte: dos autores.

Outra questão que chama a atenção é o número de pessoas que vivem na mesma residência do atendido pelo programa PELC. A maior parte dos atendidos, $54,01 \%$, possui de um a quatro moradores residentes em suas casas; $41,81 \%$, de cinco a sete pessoas por família; $2,79 \%$, de sete a nove pessoas por família; e 1,39\%, de nove a onze pessoas por família. (Tabela 3 e Gráfico 3).

5 Salário mínimo de R \$ 415,00 (01/03/2008). 
Tabela 3 - Número de residentes por atendido pelos núcleos do PELC

\begin{tabular}{|l|c|c|c|}
\hline \multicolumn{1}{|c|}{ Número } & Frequência & Percentual (\%) & Percentual Válido (\%) \\
\hline Um a quatro & 155 & 53,08 & 54,01 \\
\hline Cinco a sete pessoas & 120 & 41,10 & 41,81 \\
\hline Sete a nove pessoas & 8 & 2,74 & 2,79 \\
\hline Nove a onze pessoas & 4 & 1,37 & 1,39 \\
\hline Total & 287 & 98,29 & 100,00 \\
\hline Não responderam & 5 & 1,71 & \\
\hline Total & 292 & 100 & \\
\hline
\end{tabular}

Fonte: dos autores.

Gráfico 3 - O número de pessoas residentes por atendido pelo PELC

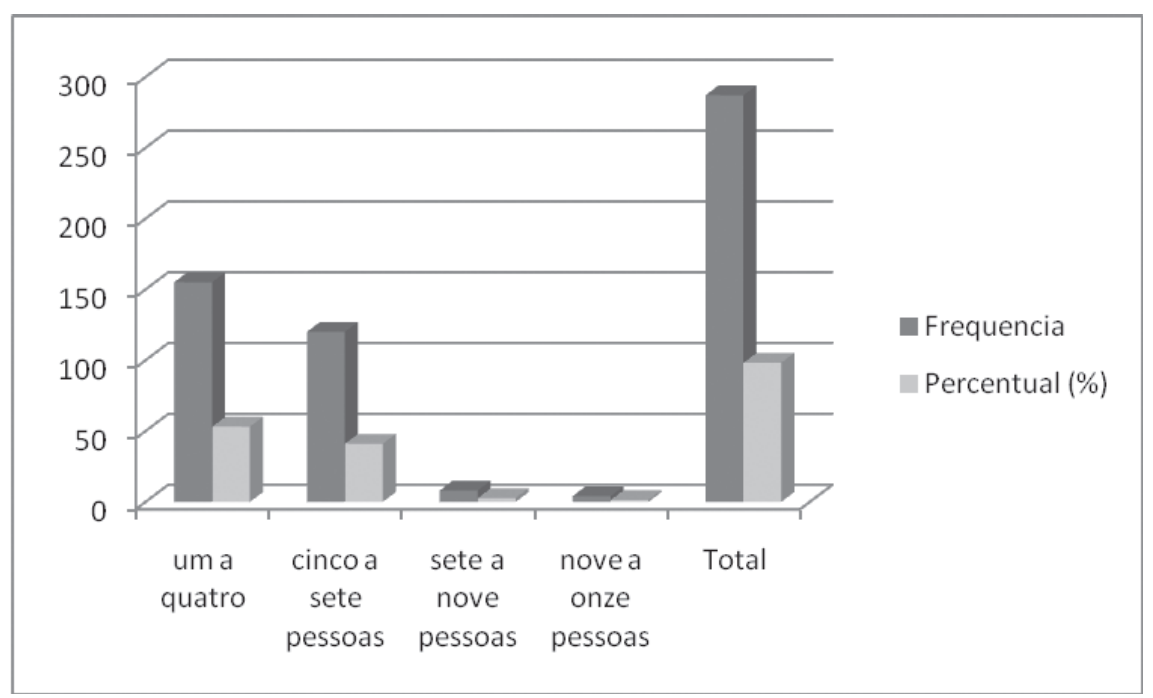

Fonte: dos autores.

Outro aspecto levantado foi a participação das bolsas sociais que complementam a renda familiar dos atendidos pelo Programa. Foi identificado que quem recebe de dois salários mínimos para baixo utiliza as bolsas sociais como complemento, com $62,69 \%$ do total. Os demais, $37,31 \%$, representam as faixas de renda de mais de três salários mínimos (Tabela 4). 
Além dos programas Bolsa Escola do Governo Federal e Minha Renda do GDF, outros foram listados pelos participantes como utilizados no processo de composição da renda familiar e, em alguns casos, não necessariamente transferem renda. Foram citados: Clube da Saúde, Instituto Superar, o Programa Pão e Leite, o Pró Jovem e o Programa Segundo Tempo.

Tabela 4 - Atendidos pelo PELC que recebem bolsas sociais do governo local e do governo federal

\begin{tabular}{|l|c|c|c|c|}
\hline \multicolumn{1}{|c|}{ Renda Familiar } & Não & Sim & $\begin{array}{c}\text { Percentual com bolsa social } \\
\text { (\%) }\end{array}$ & $\begin{array}{c}\text { Percentual } \\
\text { sem bolsa } \\
\text { social (\%) }\end{array}$ \\
\hline $\begin{array}{l}\text { Menos de um salário } \\
\text { (R\$ 430,00) }\end{array}$ & 31 & 6 & 2,38 & 12,30 \\
\hline Um salário (R\$ 430,00) & 59 & 10 & 3,97 & 23,41 \\
\hline Dois salários (R\$ 860,00) & 68 & 4 & 1,59 & 26,98 \\
\hline Três salários (R\$ 1.290,00) & 44 & 2 & 0,79 & 17,46 \\
\hline Mais de três salários & 50 & 5 & 1,98 & 19,84 \\
\hline Total & 252 & 27 & 10,71 & 100,00 \\
\hline
\end{tabular}

Fonte: dos autores.

Foi constatado que a maior parte dos atendidos pelo Programa frequenta os núcleos mais próximos de suas casas. $\mathrm{O}$ único caso em que isso não acontece é na ARUC, no Cruzeiro, onde mais de 77,49\% moram em outras localidades. Somente na Estrutural, são 40,59\% de participantes que frequentam a instituição (Tabela 5).

Tabela 5 - Número de participantes que frequentam o núcleo mais próximo de onde residem

\begin{tabular}{|l|c|c|c|c|c|}
\hline \multirow{2}{*}{$\begin{array}{c}\text { Cidade de } \\
\text { residência }\end{array}$} & \multicolumn{4}{|c|}{ Endereço do núcleo que frequentam } & \multirow{2}{*}{ Total } \\
\cline { 2 - 6 } & Samambaia & Cruzeiro & Taguatinga & Valparaiso & \\
\hline Samambaia & 23 & 1 & 0 & 0 & 24 \\
\hline Cruzeiro & 0 & 60 & 0 & 0 & 60 \\
\hline Taguatinga & 0 & 2 & 8 & 0 & 10 \\
\hline Valparaíso & 0 & 2 & 0 & 90 & 92 \\
\hline Santa Maria & 0 & 1 & 0 & 6 & 7 \\
\hline Estrutural & 0 & 33 & 0 & 0 & 33 \\
\hline Sudoeste & 0 & 3 & 0 & 0 & 3 \\
\hline
\end{tabular}


Continuação

\begin{tabular}{|l|c|c|c|c|c|}
\hline \multirow{2}{*}{$\begin{array}{l}\text { Cidade de } \\
\text { residência }\end{array}$} & \multicolumn{4}{|c|}{ Endereço do núcleo que frequentam } & \multirow{2}{*}{ Total } \\
\cline { 2 - 5 } & Samambaia & Cruzeiro & Taguatinga & Valparaiso & \\
\hline Asa Norte & 0 & 2 & 0 & 0 & 2 \\
\hline Guará & 0 & 1 & 0 & 0 & 1 \\
\hline Ceilândia & 0 & 6 & 4 & 0 & 10 \\
\hline Sobradinho & 0 & 1 & 0 & 0 & 1 \\
\hline Jardim Ingá & 0 & 1 & 0 & 0 & 1 \\
\hline $\begin{array}{l}\text { Parque } \\
\text { Mingone II GO }\end{array}$ & 0 & 1 & 0 & 0 & 1 \\
\hline SIA & 0 & 2 & 0 & 0 & 2 \\
\hline Planaltina & 0 & 2 & 0 & 0 & 2 \\
\hline Park Way & 0 & 1 & 0 & 0 & 1 \\
\hline Vicente Pires & 0 & 4 & 0 & 0 & 4 \\
\hline $\begin{array}{l}\text { Cruzeiro do } \\
\text { Sul }\end{array}$ & 0 & 0 & 0 & 2 & 2 \\
\hline Águas Claras & 0 & 0 & 1 & 0 & 1 \\
\hline Total & 23 & 123 & 13 & 98 & 257 \\
\hline
\end{tabular}

Fonte: dos autores.

\subsection{Aspectos geográficos}

Depois de gerados os mapas de localização dos cinco núcleos avaliados, foram feitas análises relativas ao grau de abrangência de cada um em relação à sua região administrativa ou município (Figuras de 2 a 6). Na maioria dos casos, com exceção dos núcleos localizados no município de Valparaíso-Go, em um raio de 400 metros, existem quadras esportivas, praças ou escolas públicas que poderiam ser aproveitadas pelas comunidades e pelos núcleos para a execução de suas atividades recreativas e de prática esportiva. Em relação aos núcleos de Valparaíso, não conseguimos dados cartográficos digitais do município; dessa forma, não foi possível analisar a possibilidade de utilização de equipamentos de esporte e lazer.

Com o auxílio das ferramentas de Geoprocessamento, especificamente o GPS e o Sistema de Informações Geográficas (SIG), foi possível avaliar em termos espaciais a localização dos núcleos nas RAs do Distrito Federal e no município de Valparaiso em Goiás, assim como a disposição dos equipamentos de esporte e lazer nas proximidades dos mesmos. Da mesma forma, foi possível gerar uma base de dados geográfica considerável, que pode subsidiar os tomadores de decisões na 
área de gestão do esporte e lazer nas cidades, notadamente aqueles do Ministério do Esporte.

Os espaços públicos de esporte e lazer, como visualizado nos mapas, poderiam ser mais bem aproveitados pelas comunidades onde esses se inserem. Da mesma forma, dada à proximidade, é de se supor que os núcleos do PELC, poderiam utilizá-los, o que daria uma melhor condição e qualidade de atendimento aos cidadãos que os frequentam. É possível que esteja ocorrendo uma subutilização desses equipamentos por parte da população e mesmo pelos núcleos.

Essa questão relativa ao acesso e uso dos equipamentos aponta para outra problemática, mais abrangente, referente à disposição dos equipamentos de esporte e lazer pelo planejamento e gestão das cidades. Onde seria mais importante a colocação de quadras esportivas e praças em uma cidade? Essa seria uma pergunta interessante a ser feita para arquitetos, engenheiros e urbanistas, em tese, os planejadores da maioria das cidades modernas.

A localização desse tipo de equipamento urbano deveria levar em consideração as reais necessidades das comunidades urbanas e os padrões de acesso e utilização pelas populações, tema que requer maiores estudos. 
Figura 2 - Núcleo do PELC ACL - Taguatinga-DF.

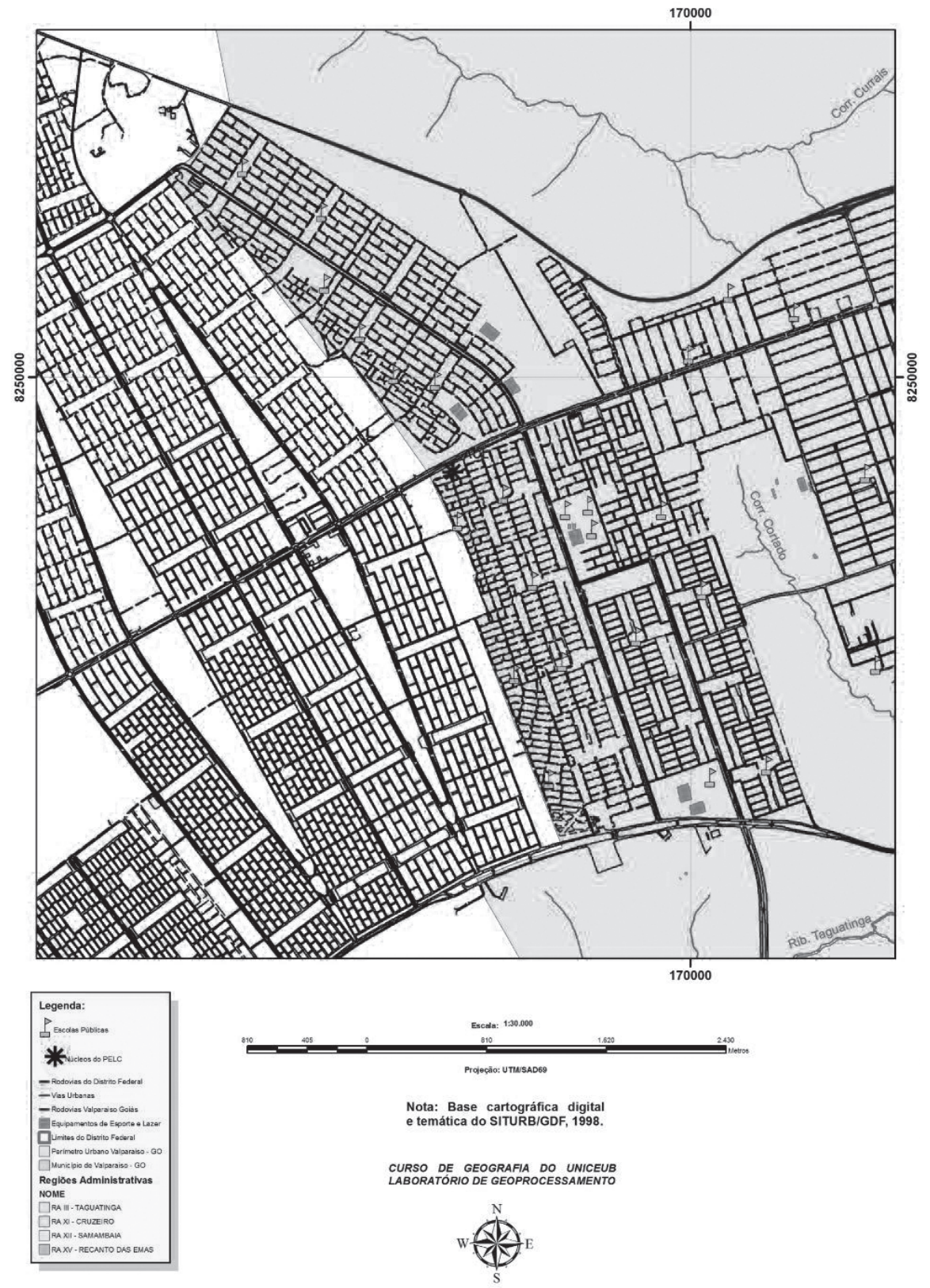

Fonte: dos autores. 
Figura 3 - Núcleo do PELC ACEC - Samambaia - DF.
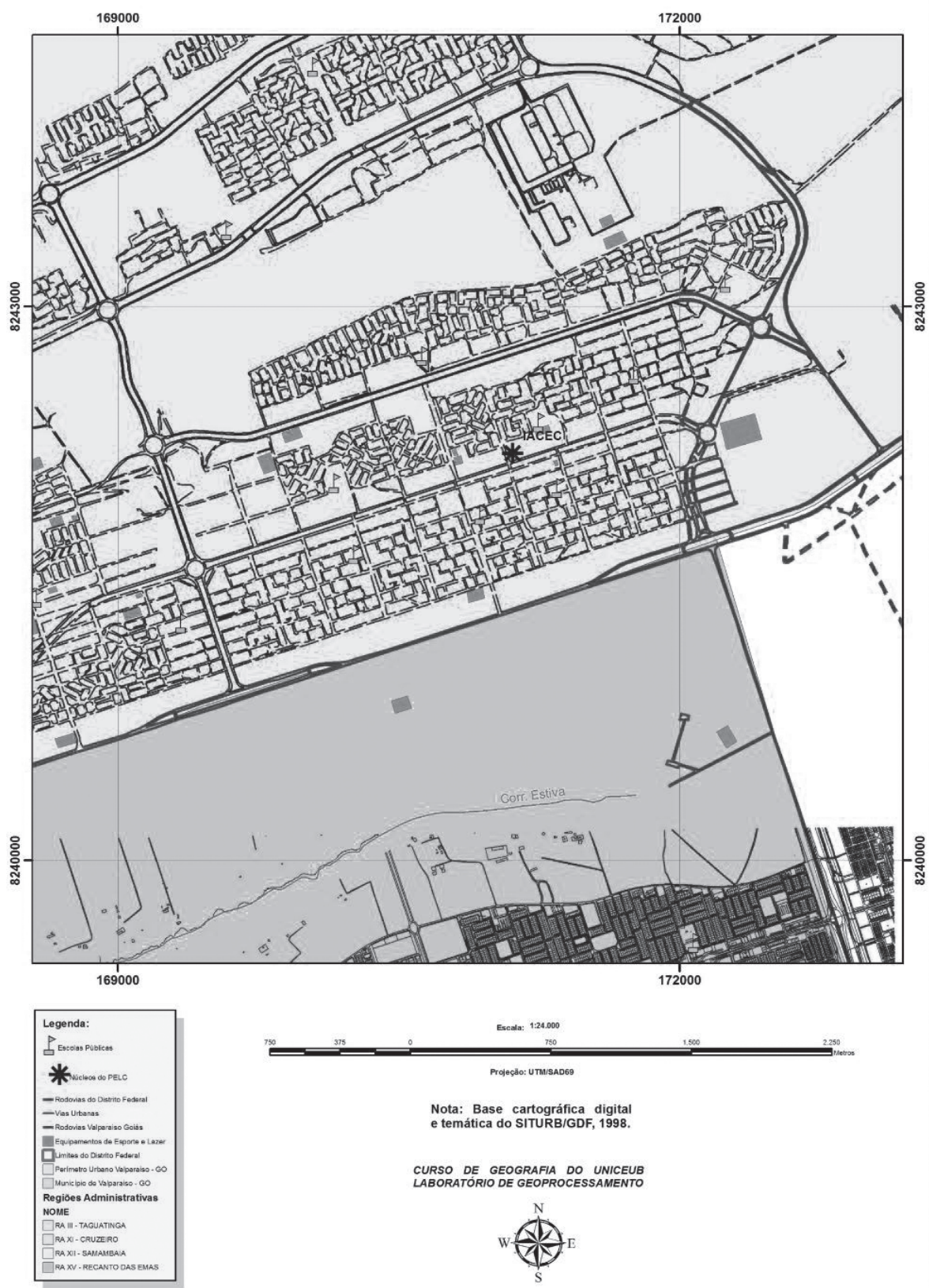

Fonte: dos autores. 
Figura 4 - Núcleo do PELC ARUREMAS - Recanto das Emas - DF.

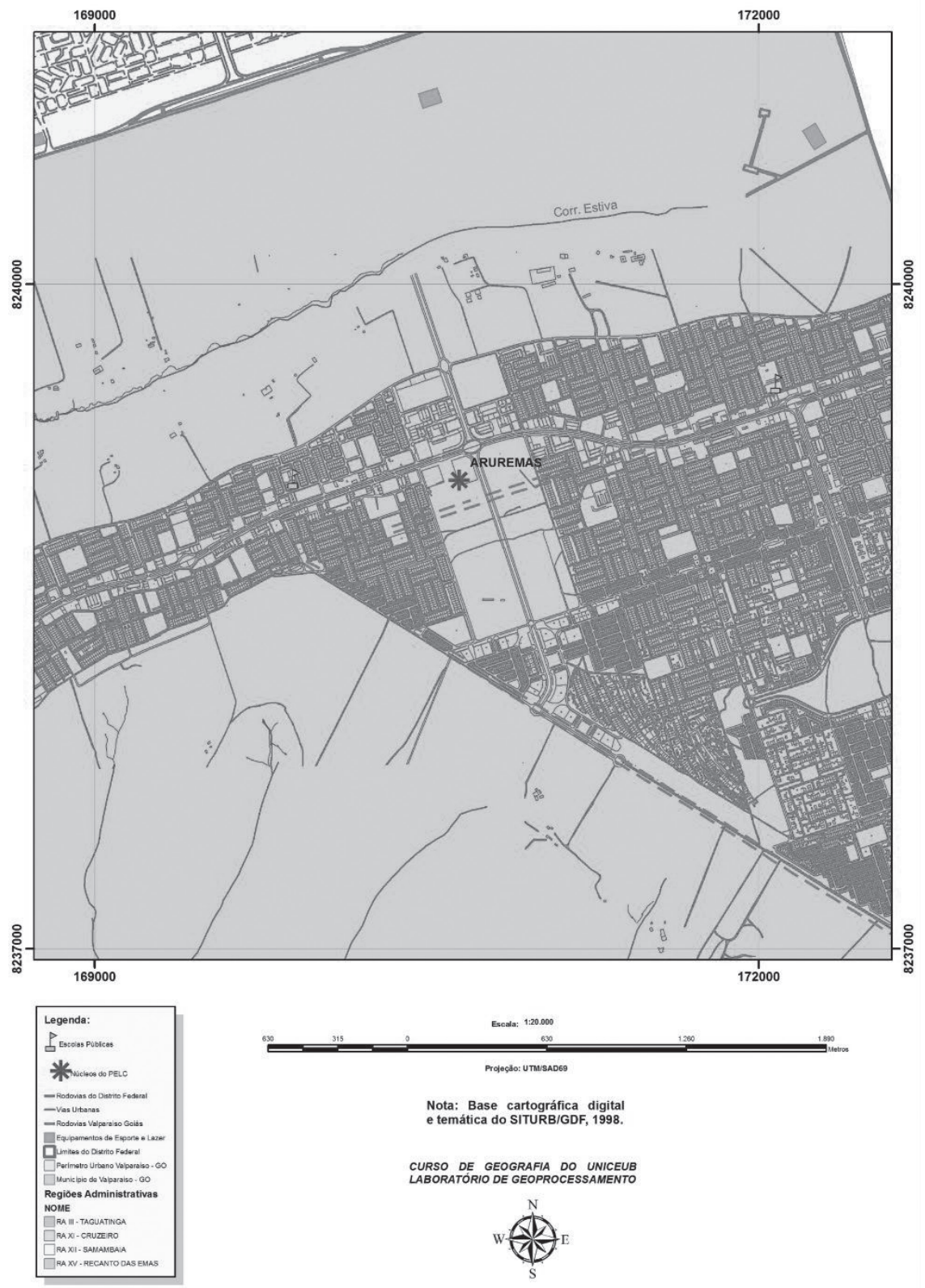

Fonte: dos autores. 
Figura 5 - Núcleo do PELC ARUC - Cruzeiro - DF.

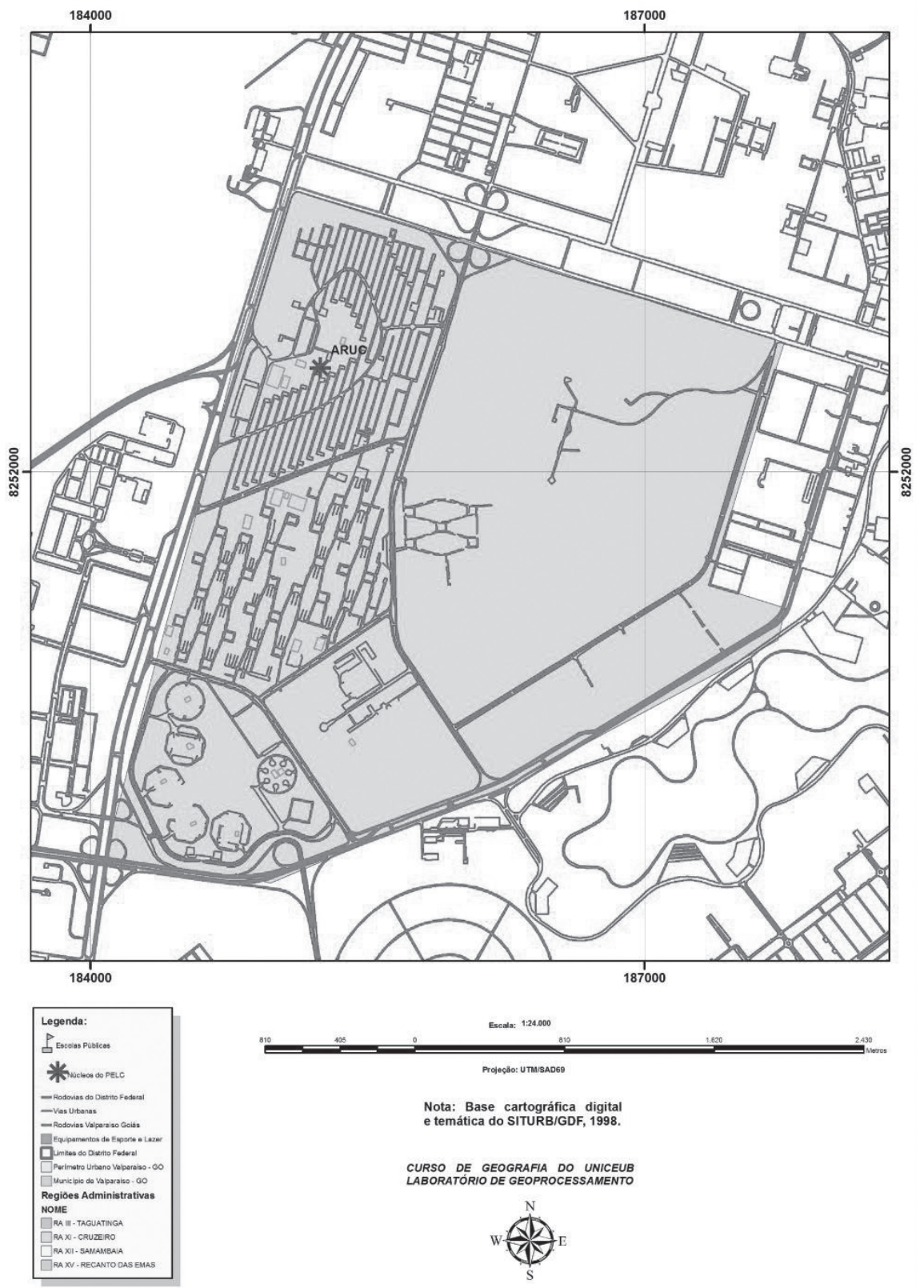

Fonte: dos autores. 
Figura 6 - Núcleos do PELC JUDEC e Vem Viver - Valparaiso - GO.

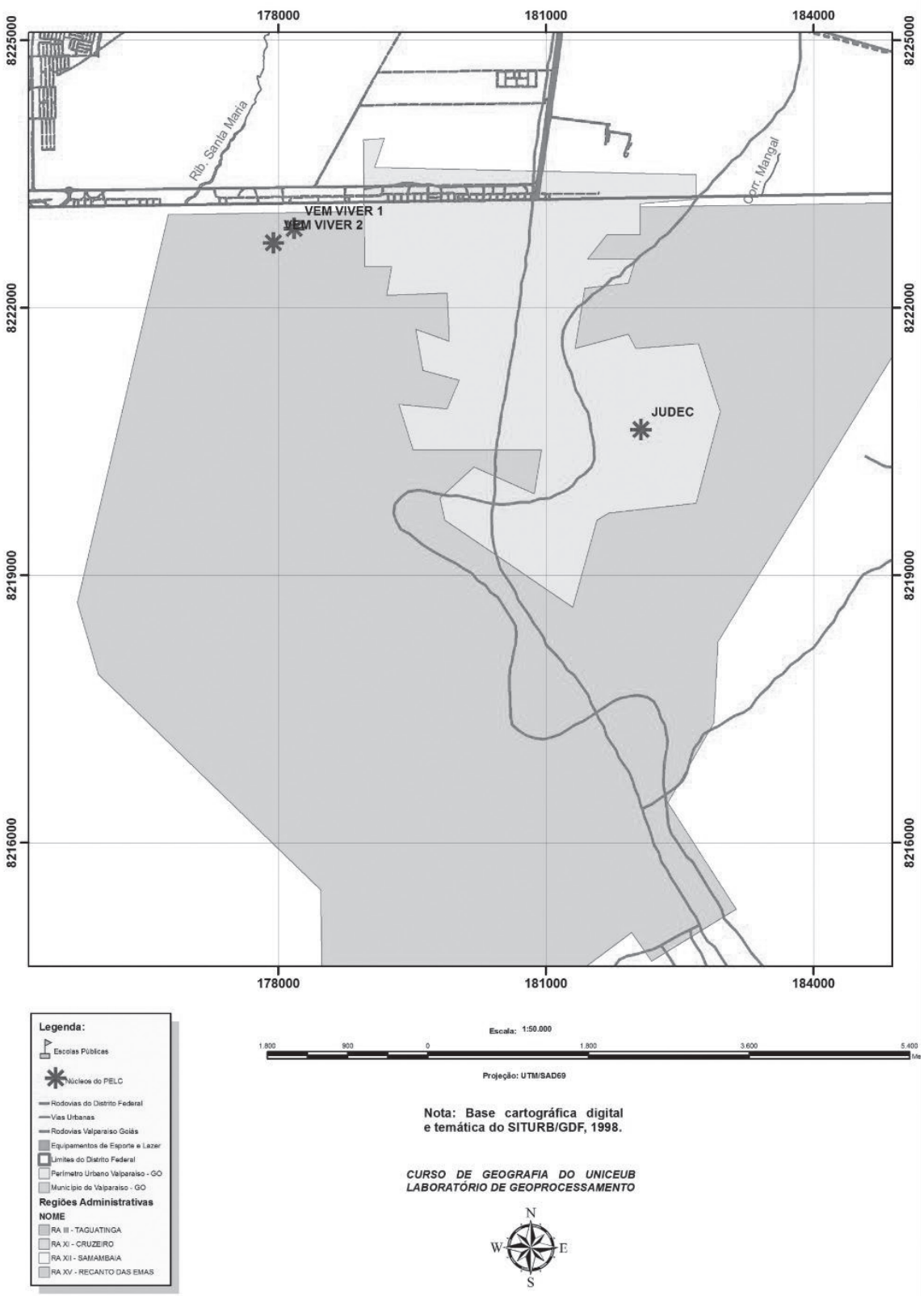

Fonte: dos autores. 


\section{Considerações finais}

Os levantamentos demonstraram que os núcleos avaliados atendem às populações que residem mais próximas à sua localização. Os deslocamentos até os núcleos são bem curtos, o que facilita o acesso dos atendidos pelo Programa.

De modo geral, os núcleos do PELC atendem às comunidades com características marcantes de desigualdades sociais. Dessa forma, o Programa vem complementar alguns aspectos dos programas sociais desenvolvidos pelo governo federal e do Distrito Federal. O único problema, nesse caso, foi a escolha do núcleo da ARUC, no Cruzeiro, pois ele atende mais aos participantes moradores da Região Administrativa da Vila Estrutural, do que aos moradores da própria Região Administrativa em questão. O nível social e o nível de renda dessa RA não se enquadram nos princípios do próprio Programa PELC.

É possível afirmar que a zona de cobertura dos núcleos não é muito abrangente, o que poderia apontar para a pertinência de se dinamizar mais núcleos por RA.

As políticas públicas elaboradas com o objetivo de equalizar os problemas urbanos, e também do esporte e do lazer, poderiam trabalhar as questões comuns desses dois temas, de modo a aproveitar melhor os espaços públicos e promover atividades que envolvessem as comunidades que habitam essas áreas urbanas modernas.

A participação do profissional de Educação Física e de Geografia nos processos de proposição, implantação e coordenação de programas que ligam o esporte e o lazer a políticas públicas de cunho social é cada vez mais evidente. No caso do PELC, é preocupante o fato de que a maior parte dos responsáveis pelos núcleos, os coordenadores ou os agentes sociais de esporte e lazer não tenham a formação necessária à execução dos objetivos do Programa. 


\section{Public policies for sport and recreation in cities: socioeconomic and geographical aspects of Sport and Recreation Program in the Cities - PELC, Ministry of Sports}

\section{Abstract}

This study examines the program of the City Sporting Goods - PELC, the Ministry of Sports. Initially, data were presented on the PELC is the core responsibility of evaluation by the Center for Development of Sports Recreation and Leisure, Faculty of Physical Education at UNB. In general the nuclei are located in areas of the Federal District and the city of Valparaiso - GO characteristically low-income, where families survive on two minimum wages and have up to five people on average. The main objective of this study was to carry out an initial assessment of the socioeconomic and geographic PELC, regarding the implementation of public policies for low-income populations, specifically in the nuclei of the program in the Federal District in a surrounding municipality. Questionnaires were administered to program participants in order to assess the level of family income and achieve the social profile of the communities served. All cores were located geographically with the use of geoprocessing tools. In serving poor communities, the program complements some aspects of the social programs developed by the Federal Government and the Federal District. Public policies designed in order to equalize the urban problems and also sport and leisure, could work through the issues common to these two themes in order to make better use of public spaces and promote activities that involve communities living in these modern urban. It was found that in the case of PELC, the most responsible for the core - the coordinators or social activists, sports and leisure - do not have the necessary training to implement the goals of the program.

Keywords: Sport. Recreation. Cities. Public policy. 


\section{Referências}

ADAMS, José Rodrigo Barth. Esporte, lazer e cidadania emancipatória: algumas aproximações. In: SEMINÁRIO NACIONAL SOCIOLOGIA E POLÍTICA, Sociedade e Política em Tempos de Incerteza, Grupo de Trabalho 9 - Estudos Socioculturais do Esporte, 1, 2009, Curitiba. Anais... Curitiba: UFPR, 2009.

AZEVEDO, Janete M. Lins de. A educação como política pública. Campinas: Autores Associados, 1997.

BRASIL. Constituição (1988). Constituição da República Federativa do Brasil. Brasília: Congresso Nacional, 1988.

BRASIL. Lei No 10.836, de 09 de janeiro de 2004. Cria o Programa Bolsa Família e dá outras providências. Diário Oficial da União, Brasília, n. 95, 12 janeiro 2004. Seção 1. p. 1.

BRASIL. Ministério do Esporte. Lista de projetos classificados para conveniamento imediato. In: . Edital 2010 do Programa Esporte e Lazer da Cidade. Brasília, 2010b. p. 1-5.

BRASIL. Ministério do Esporte. Manual de Orientações para Implementação do Programa Esporte e Lazer da Cidade. Brasília, 2010a.

BRUST, Cristina; BAGGIO, Isabel Cristina; SALDANHA FILHO, Matheus Francisco. Repensar a gestão das políticas públicas de esporte e lazer: o caso de Santa Maria/RS. Motrivivência. Local, ano 18, n. 27, p. 179-192, dez. 2006.

CASTELLANI FILHO, Lino. Gestão pública e política de lazer: a formação de agentes sociais. Campinas: Autores Associados, 2007.

CASTELLS, M. A sociedade em rede. São Paulo: Paz e Terra, 1999.

DISTRITO FEDERAL. Governo do Distrito Federal (GDF). Principais programas sociais, 2010. Disponível em: < http://www.df.gov.br/005/00502001.asp?ttCD_ CHAVE $=1766>$. Acesso em: 6 set. 2010.

DISTRITO FEDERAL. Governo do Distrito Federal (GDF). Síntese de informações socioeconômicas. Companhia de Planejamento do Distrito Federal (Codeplan). Brasília: Codeplan, 2008. 89 p.

DUMAZEDIER, Jofre. Lazer e cultura popular. São Paulo: Perspectiva. 2001. 333 p. 
FIGUEIREDO, Pedro Osmar Flores de Noronha. Política e formação: o Programa Esporte e Lazer da Cidade no Distrito Federal e Entorno. 2009. 136 f. Dissertação (Mestrado)-Programa de Pós-Graduação em Educação Física, Universidade de Brasília, Brasília, 2009.

GEIGER, Pedro G. A urbanização brasileira nos novos contextos contemporâneos. In: GONÇALVES, Maria F. (Org.). O novo Brasil urbano: impasses, dilemas, perspectivas. Porto Alegre: Mercado Aberto, 1995. p. 23-65.

HATTNER, Henrique. Planejamento urbano e regional. 2. ed. São Paulo: Nacional, 1978.

IBGE, Instituto Brasileiro de Geografia e Estatística. Brasil em Números. Rio de Janeiro, v. 15, p. 1-349, 2007.

MENDES, Roseana; CUNHA JUNIOR, Carlos Fernando F. da. Compreensões sobre o lazer. Licere, Belo Horizonte, v. 12, n. 3, p. 1- 19, set. 2009.

OLIGARI, Tatiana C. O Sistema de Planejamento Territorial e Urbano do Distrito Federal a partir da década de 90: uma avaliação dos Planos Diretores Locais de Sobradinho e Taguatinga. 2002. p. 194. Dissertação (Mestrado)-Departamento de Urbanismo (DeU), Faculdade de Arquitetura e Urbanismo (FAU), Universidade de Brasília (UnB), Brasília, 2002.

ROSA, Roberto. Geotecnologias na geografia aplicada. Revista do Departamento de Geografia, São Paulo: USP. v. 16, p. 81-90, set. 2005.

SANTOS, M. A natureza do espaço: técnica e tempo, razão e emoção. São Paulo: Hucitec, 1996.

SANTOS, Milton. Os caminhos da reflexão sobre cidade urbana. São Paulo: Universidade de São Paulo, 1992.

SOUZA, Marcelo L. Mudar a cidade: uma introdução crítica ao planejamento e à gestão urbanos. Rio de Janeiro: Bertrand, 2002.

SUASSUNA, Dulce Maria Filgueira de Almeida. O programa esporte e lazer da cidade: a política de formação para o trabalho e o papel dos agentes sociais. In: CONGRESSO BRASILEIRO DE CIÊNCIAS DO ESPORTE, 16.; CONGRESSO INTERNACIONAL DE CIÊNCIAS DO ESPORTE, 3., 2009, Salvador. Anais... Salvador: CBCE, 2009. p. 1-11. 
VIEIRA, Liszt; BREDARIOL, Celso. Cidadania e política ambiental. Rio de Janeiro: Record, 1998. 